\title{
Effect of Sub-Inhibitory Concentrations of Flucloxacillin or Clindamycin and Plasma on Staphylococcus aureus Clinical Isolate
}

\author{
Hanson Ige Ogbu, Chigalunwo Ada Joseph
}

\begin{abstract}
Concentrations of antibiotics below the minimum inhibitory concentration encourages the overgrowth of organisms and the reason they survive is because they are resistant to the drugs prescribed and so able to proliferate quickly, assisted by the sudden access to nutrients and space.This palpable reality is a potential threat to the future of health care delivery and forms a basic consideration in the present study. The influence of sub inhibitory doses of Flucloxacillin or Clindamycin and plasma on Staphylococcus aureus clinical isolate was investigated using standard methods. The immune system is represented with fresh, preserved human plasma freeonly of erythrocytes. The study showed that human plasma can slow growth of invading organisms, even though this will have to be considered alongside the number of the invading organism and time it takes for antibodies to be produced. The exposure of the test organism to sub-minimum inhibitory concentrations of flucloxacillin and clindamycin showed clear resistance against the two test antimicrobial agents but significantly against the narrow spectrum flucloxacillin.This further illustrates effect ofadministering sub-therapeutic concentrations of antibiotics and the consequences ofthe invading organism acquiring resistance.Itis hoped that this research will lead to a reexamination of how antibiotics areadministered for management of patients suffering from recurrent S. aureus related diseases.
\end{abstract}

Index Terms- Clindamycin, Flucloxacillin, Immune system, Plasma, Staphylococcus aureus, Sub-inhibitory concentration,

\section{INTRODUCTION}

Staphylococcus aureus is an important human pathogen responsible for a wide array of infections such as endocarditis, scalded skin syndrome, septic arthritis, osteomyelitis,toxic shock syndrome, septic arthritis, device associated infections, a relatively rare, toxin-mediated disorder, skin and soft tissue infections. [1-5] When the human body come under attack from this bug, the job of protecting it shifts to the body immune system. [6]The immune system is a complex network of cells, signals, and organs that work together to detects and eliminates invaders, pathogensthat cause infections. $[6,7]$

Hanson I. Ogbu, Department of Pharmaceutical Microbiology \& Biotechnology, Faculty of Pharmaceutical Sciences, University Park, University of Port Harcourt, Nigeria

Chigalunwo Ada Joseph, Department of Pharmaceutical Microbiology \& Biotechnology, Faculty of Pharmaceutical Sciences, University Park, University of Port Harcourt, Nigeria
As a matter of necessity, the immune system must also recognize the body's own self cells, so they are not mistaken for invaders[8]and the functioning of the immune system is referred to as immune response. [6]Based on the immune response, immunity is classified into innate and acquired immunity.[7]The acquired immunity, has been reported to be involved in the production of special plasma proteins, called immunoglobulins or antibodies, which enables the host to mount a more rapid and efficient immune response upon subsequent exposure to the antigen.[6, 7]Plasma cellsare not only capable of secreting high specialized antibodies, but assist in the transportation of certain agents, such as leukocytes, macrophages, drugs and alcohol, which make it an important inhibitory environment for invading pathogens. [9] Previous studies by Okoreet al. [9] indicates that a patient's immune system may become very weak and not able to get rid of invading pathogens and in such circumstances, medication maybe required to fight the infection.It is common knowledge that a lot of people of developing countries especially in the third world countries practise self-medication while a lot more would not take their medication correctly. [9]This practice exposes the invading organisms to sub-inhibitory doses of the drugs.Sub inhibitory concentrations, is known to stimulate mutation and, consequently, bacterial adaptation to different stresses, including antibiotic pressure. [10] and has become a course for concern worldwide. $[9,11,12]$ The inappropriate use of antibiotics for different human activities and the uncontrolled abuse of these compounds for therapeutic purposes has had a major impact, leading to the selection and spread of resistant. [10, 13]Thisphenomenonhas resulted in the selection of pre-existing resistant variants that ultimately become fixed in our communities. [10]Several other authors have also noted the expression of virulence functions such as toxins, adhesins, and biofilm formation in the human pathogen $S$. aureusto be the direct result of exposure to sub-minimal inhibitory concentration (sub-MIC) of antibiotics. [14-16] Sub inhibitory concentrations of antibiotics are reported to provoke extensive transcriptional changes in bacteria, $[16,17]$ especially with compounds whose primary mode of action is DNA damage. [18]Cirz and Romesberg[19] in their work noted the phenomenon to be the result of transcriptional changes in the genes responsible for DNA repair and preservation of the integrity of the genome, such as the SOS and methyl mismatch repair (MMR) pathways. Previous studies by López and Blázquez[10]suggest that bacteria are not simply passive subjects during the process of evolution by mutation and 
natural selection and that by means of SOS induction, antibiotic such as fluoroquinolone may stimulate mutations and the horizontal transfer of DNA sequences. [10, 20] Similar studies have shown the evolution of antibiotic resistance to be based on genetic variation and selection of the genotypes generated by this variation. According to López and Blázquez[10]the spontaneous generation of genetic variation in bacteria, particularly in nature is supposedly based on the strategies of small local changes in the nucleotide sequence of the genome (mutation), intragenomic reshuffling of genomic sequences (intrachromosomal recombination), and the acquisition of DNA sequences from other organisms via horizontal gene transfer. Lawrence and Roth [21]noted that the horizontal gene transfer diversification mechanism in prokaryotes and recombination as an important factor to different traits, allowing bacteria to evade the host immune response, distributing genes that increase virulence, and providing increased resistance to antibiotics.Thus, broadening our current knowledge of the effect that sub-lethal concentrations of antimicrobial agents produce on human bodyespecially when invaded by a notable human pathogen is of clinical interest. The assumption is that when a susceptible pathogen has been exposed to a sub-lethal dose of an antibiotic, its physiological system may be modified in a way that makes it less vulnerable to an active immune system.This palpable reality is a potential threat to the future of health care delivery and forms a basic consideration in the present study.

In the present study, the impact of sub-inhibitory concentration of antibiotics by a notable human pathogen is revisited. The immune system is represented with fresh, preserved human plasma free only of erythrocytes. The effect of human immune agent present in the plasma on clinical isolate of $S$. aureus that have earlier been exposed to sub-inhibitory concentrations of flucloxacillin and clindamycin was investigated. The assessment covered subinhibitory concentrations of flucloxacillin and clindamycin at $1 / 2,1 / 4,1 / 8,1 / 16$ minimal inhibitory concentrations (MICs) and viable cell counts of $S$. aureus in plasma after exposure to sub-MIC of the test agents.

\section{MATERIALS AND METHOD}

\section{A. Test Organism}

The test organism used was a clinical isolates of Staphylococcus aureus obtained from University of Port Harcourt Teaching Hospital (UPTH), Rivers State, Nigeria. The stock culture was further confirmed by standard culture, gram reaction, biochemical test and maintained on slopes of modified nutrient agar at $4{ }^{\circ} \mathrm{Cuntil}$ ready for use. [22]

\section{B. Blood Plasma}

Twenty millilitres $(20 \mathrm{ml})$ of blood sample was aseptically obtained using a sterile $20 \mathrm{ml}$ syringe from two volunteer and aseptically transferred into Vacutainer blood collection tube containing and anticoagulant. The blood was spanned in a centrifuge until the cells were settled at the bottom of the tube. The plasma was then collected aseptically using a sterile syringe and stored at four degree Celsius until ready for use.

\section{Ethical considerations}

This study was approved by the research and ethics committee of University of Port Harcourt Teaching Hospital, Rivers State. All samples were collected following voluntary informed consent of the participants. Patient's data were handled confidentially and in accordance with approved protocols of handling patient data.

\section{Culture Media}

The media used in this study were Nutrient Agar, Nutrient broth (Titan Biotech Ltd India). The media were constituted according to manufacturer's specification. Sterilization was by autoclaving at $121{ }^{\circ} \mathrm{C}$ for $15 \mathrm{~min}$ and maintained in molten as previously described. ${ }^{[23-25]}$

\section{E. Antimicrobial Agents Used}

The antimicrobial agents used were Flucloxacillin $(250 \mathrm{mg})$ and Clindamycin (300 mg). Both were obtained from approved Pharmacy outlets within Port Harcourt Metropolis, South-south region, Nigeria. The antibiotic samples were inspected to ensure that manufacturer's information, batch numbers, manufacturing and expiry dates, National Agency for Food and Drug Administration and Control (NAFDAC) Registration Number were provided. Thereafter, samples were transported to pharmaceutical microbiology laboratory, University of Port Harcourt for analysis.

\section{F. Preparation of Test Antibiotics}

A stock solution of $1 \mathrm{mg} / \mathrm{ml}$ of Clindamycin was aseptically prepared by dissolving $300 \mathrm{mg}$ of Clindamycin in $300 \mathrm{ml}$ of sterilized water while that of flucloxacillin was by dissolving $500 \mathrm{mg}$ of the drug in $25 \mathrm{ml}$ of sterile water to obtain stock of $20 \mathrm{mg} / \mathrm{ml}$.

\section{G. Standardization of test organism.}

The standardization of inoculums was carried out by adjusting the turbidity of the microbial suspension to match the turbidity of $0.5 \mathrm{McF}$ arland Standards. This is equivalent to approximately $1.5 \times 10^{8} \mathrm{cfu} / \mathrm{mL}$ of bacterial suspension, when the turbidity values of the two suspensions match optically or visually as previously described. ${ }^{[6]}$

\section{H. Determination of Minimum Inhibitory Concentration (MIC)}

Minimum inhibitory concentration of Clindamycin and Flucloxacillin were carried out using two-fold serial macrodilution in nutrient broth. The stock concentration was diluted serially to produce several dilutions in decreasing order of concentrations. To the first tube containing $5 \mathrm{ml}$ of sterile double strength nutrient broth, $5 \mathrm{ml}$ of the test antimicrobial agent was added and mixed thoroughly. Thereafter $5 \mathrm{ml}$ was transferred from the first tube to the second containing $5 \mathrm{ml}$ of single strength nutrient broth and the process repeated sequentially until the last tube. $0.1 \mathrm{ml}$ of the test culture was then inoculated into each of the dilutions and incubated at $37{ }^{\circ} \mathrm{C}$ for 48 hours. Microbial growth was examined visually for the presence of turbidity the lowest concentration of the agent that showed no growth was noted as the MIC. ${ }^{[6]}$

\section{Determination of Sub-MIC}

From the MIC concentrations, a stock solution that is half ( $1 / 2$ or $50 \%, 1 / 4$ or $25 \%, 1 / 8$ or $12.5 \%$ and $1 / 16$ or $6.25 \%$ ) of the MIC of both drugs were prepared aseptically as 
previously described. ${ }^{[6]} 0.1 \mathrm{ml}$ of the test organism was aseptically inoculated into the respective tubes containing the different sub-MIC concentrations of clindamycin and flucloxacillin.The tubes were incubated at 37 degree Celsius for 24 hours and examined for the presence of turbidity. [9]

\section{J. Sub-MIC of Clindamycin or Flucloxacillinand Plasma}

The cells obtained from the different sub-MIC concentrations of the test antimicrobial agents were washed twice respectively using $10 \mathrm{ml}$ normal saline by spinning in the centrifuge and decanting the supernatant at the end of each wash to obtain the cell sediment. $0.5 \mathrm{ml}$ of normal saline and $0.5 \mathrm{ml}$ of plasma were aseptically added to the washed cells and gently shaken to ensure they've been properly mixed.At an interval of 0 minute, 1, 2, 3, 4 and 5 hours a $0.1 \mathrm{ml}$ of the reaction mixture was withdrawn and transferred into tubes containing molten nutrient agar, swirled, poured onto sterile disposable Petri dishes and allowed to solidify on the bench.The Petri dishes were then incubated at 37 degrees Celsius for 24 hours and cells that survived the combined antibiotic plasma reaction were counted as previously described.[9]

\section{K. Statistical analysis}

The data obtained on activities of the test antibiotics against the test isolates were analysed using One - way analysis of variance (ANOVA). All the data were computed as means \pm standard deviation using GraphPad Prism 7. Probability value of less than or equal to 0.05 is considered to be statistically significant.

\section{RESULTS}

\section{A. Minimum inhibitory Concentration}

The minimum inhibitory concentration of the test antimicrobial agents (Clindamycin and Flucloxacillin) against the test organism (S. aureus) are represented in Fig. 1 and 2. As shown, the MIC of flucloxacillin $(5 \mathrm{mg} / \mathrm{ml})$ is significantly higher than that of clindamycin $(0.25 \mathrm{mg} / \mathrm{ml})$. This is an indication than clindamycin is more effective in the management of infections caused by $S$. aureus. The MICs obtained at different sub-MIC concentrations of clindamycin ranges from 0.250 to $0.500 \mathrm{mg} / \mathrm{ml}$ and that of flucloxacillin ranges from 10 to $50 \mathrm{mg} / \mathrm{ml}$. At 1/2,1/4,1/8 and $1 / 16$ sub-MIC concentrations were $0.250,0.500,0.375$ and $0.375 \mathrm{mg} / \mathrm{ml}$ for clindamycin and $10,25,25$, and $50 \mathrm{mg} / \mathrm{ml}$ respectively for flucloxacillin. The organisms exposed to the sub-MIC of flucloxacillin acquired resistance after being exposed to sub-MIC of flucloxacillin but there was little, or no resistance acquired by the organisms exposed to clindamycin after exposure.

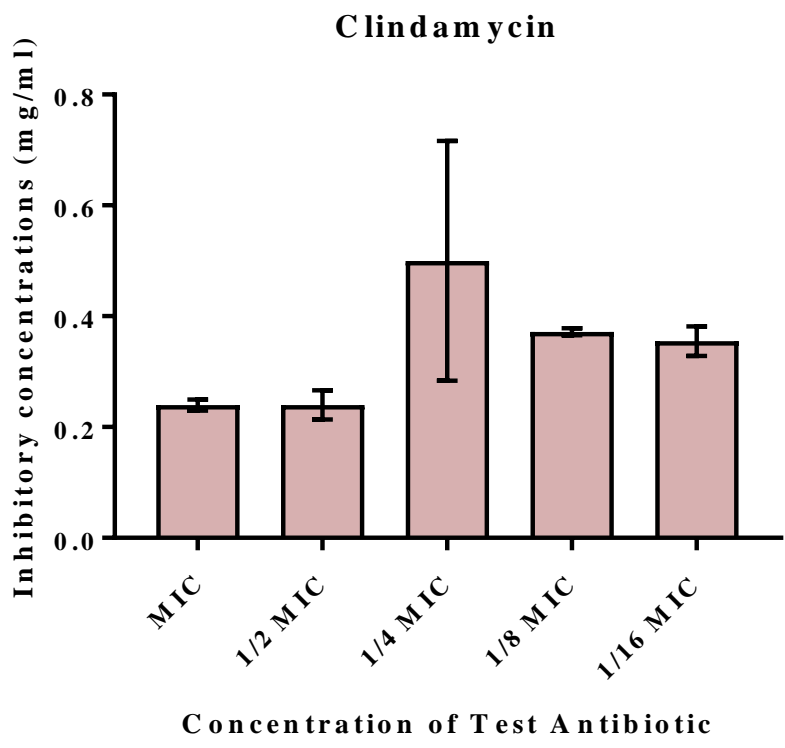

Fig. 1: Column chart showing inhibitory concentrations produced by Clindamycin against test organism after exposure to plasma. Data shown are from three independent cultures with significant difference among means $(\mathrm{P}$ value $=$ $<0.05)$ and error bars indicating standard deviations.

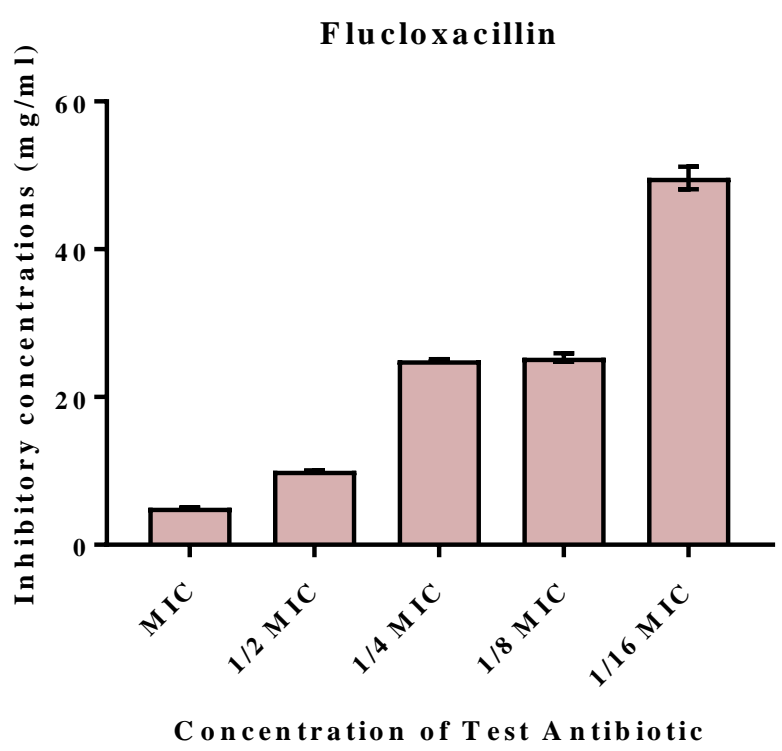

Fig. 2: Column chart showing inhibitory concentrations produced by Flucloxacillin against test organism after exposure to plasma. Data shown are from three independent cultures with significant difference among means ( $\mathrm{P}$ value $=$ $<0.05)$ and error bars indicating standard deviations.

\section{B. Viable cell counts}

The viable cell counts after exposure of the different subMIC concentrations of the test antimicrobial agents are presented in Table 1 and 2 . The viable cell count at $1 / 2$ subMIC of clindamycin and flucloxacillin ranges from 76 to $100 \mathrm{cfu} / \mathrm{ml}$ and 78 to $108 \mathrm{cfu} / \mathrm{ml}$ respectively. At 0 minute, the colonies formed for both test antimicrobial were too numerous to count but at time intervals of 1 hour, 2, 3,4 and 5 hours are $71,76,77,84$ and $100 \mathrm{cfu} / \mathrm{ml}$ respectively for clindamycin and 83, 85, 78, 101 and $108 \mathrm{cfu} / \mathrm{ml}$ respectively for flucloxacillin. Between the time of 4 and 5 hours the 
growth of the organism increased, this could be an indication that though the plasma was able to inhibit the growth of the organism to a certain growth level, with time the organism will likely thrive again. The viable cell counts at $1 / 4$ sub-MIC of clindamycin and flucloxacillin ranges from 91 to 104 colonies and 93 to 110 colonies respectively (Table 2). At the time 0 minute the colonies formed where too numerous to count this could be because the reaction occurring between the plasma is not enough in inhibiting the organism's growth. At an interval of 1 hour, 2, 3, 4 and 5 hours the colonies formed are 91, 91, 92, 104 and 104 colonies respectively for clindamycin, while 97, 95, 93, 110 and 105 colonies were formed respectively for flucloxacillin. The same pattern of increase in the number of colonies after 3 hours also occurred at $1 / 4$ concentration of the sub-MIC although there was an increase in the colonies formed when compared to that of $1 / 2$ sub-MIC. The viable cell count at $1 / 8$ and $1 / 16$ sub- MIC concentrations were too numerous to count. This simply indicates that ability of the plasma to inhibit the growth of an invading pathogen does not only depend on the time of reaction but also on the number of the organism.

Table 1: Viable cell count of test organism in plasma after exposure to sub-MICs of Flucloxacillin

\begin{tabular}{|c|c|c|c|c|c|c|}
\hline \multirow{2}{*}{$\begin{array}{c}\text { Antibiotic } \\
\text { concentrations } \\
(\mathrm{mg} / \mathrm{ml})\end{array}$} & \multicolumn{6}{|c|}{ Time (hrs)/cfu/ml } \\
\hline & $\mathbf{0}$ & 1 & 3 & 3 & 4 & 5 \\
\hline $1 / 2$ & TNTC & 83 & 85 & 54 & 101 & 108 \\
\hline $1 / 4$ & TNTC & 97 & 96 & 93 & 110 & 105 \\
\hline $1 / 8$ & TNTC & TNTC & TNTC & TNTC & TNTC & TNTC \\
\hline $1 / 16$ & TNTC & TNTC & TNTC & TNTC & TNTC & TNTC \\
\hline
\end{tabular}

TNTC $=$ Too numerous to count

Table 2: Viable cell count of test organism in plasma after exposure to sub-MICs of Clindamycin

\begin{tabular}{|c|c|c|c|c|c|c|}
\hline \multirow{2}{*}{$\begin{array}{c}\text { Antibiotic } \\
\text { Concentrations } \\
(\mathrm{mg} / \mathrm{ml}) \\
\end{array}$} & \multicolumn{6}{|c|}{ Time (hrs)/cfu/ml } \\
\hline & $\mathbf{0}$ & 1 & 3 & 3 & 4 & 5 \\
\hline $1 / 2$ & TNTC & 71 & 76 & 77 & 94 & 100 \\
\hline $1 / 4$ & TNTC & 91 & 91 & 92 & 104 & 104 \\
\hline $1 / 8$ & TNTC & TNTC & TNTC & TNTC & TNTC & TNTC \\
\hline $1 / 16$ & TNTC & TNTC & TNTC & TNTC & TNTC & TNTC \\
\hline
\end{tabular}

TNTC $=$ Too numerous to count

\section{DISCUSSION}

The effect of human immune agent present in plasma on the test microorganism following exposure to sub- inhibitory concentration of test antimicrobial agents was investigated. The result obtained in this study (Table 1 and 2) suggests that plasma cell which contains antibodies has the ability to inhibit the growth of bacterial cells to a certain limit with time. The exposure of an organism to sub-MIC concentrations of antibiotics does not mean that the microorganism will be weakened, but at sub- MIC levels of $1 / 2$ and $1 / 4$ the growth of the test organism was inhibited by plasma. Previous reports indicate that antibiotics at subMICs have numerous effects on bacteria, including morphological changes, modification of cell wall structure of the organism, altered growth kinetics, biofilm formation, inhibition of enzyme or toxin production, loss of adhesive properties of bacteria, and increases log phase of bacteria strain thus affecting bacteria virulence. [14-16, 26, 27] In a related study antimicrobial concentrations below those that results in killing of the organism has been reported to cause alterations in susceptibility to host defence mechanisms including phagocytosis, chemotaxis and complementmediated immunity.[28]At $1 / 8$ and $1 / 16$ sub-MICs the plasma was unable to inhibit the growth of the test organism as shown in this study. The MIC results after exposure to plasma also indicates that the organism has acquired resistance against the test antimicrobial agent most especially to flucloxacillin which is a narrow spectrum antibiotic (Table 2).

The major target of antimicrobial agents in S. aureus are the cell envelope, the ribosome and the nucleic acid. Resistance can either develop by horizontal transfer of gene of resistance determinant through the plasmids, the chromosome and transposons. Resistance can also be acquired horizontally through enzymatic drug modification and inactivation, enzymatic modification of drug binging site, drug efflux and by pass mechanism.[29] The ability of $S$. aureus to form biofilm is another mechanism through which the organism shows resistance. Studies have shown that $S$. aureus can produce a multi-layered biofilm embedded with a glycocalyx or slime layer protein expressed throughout; this layer has the ability to evade multiple clearance mechanisms produced by the host and synthetic sources such as shear stress, host phagocytic elimination and host radical and protease defences. [30]Cardileet al. [1] in their study showed that the exposure of clinical isolates of $S$. aureus to human plasma (10\%) within media, and to a lesser extent when coated onto plates, significantly enhanced biofilm formation. Although there is an increasing evidence that in vitro biofilm assays may not truly represent in vivo biofilms because of the possible presence of host proteins, of which human plasma is the best characterized. [31, 32]

\section{CONCLUSION}

This study shows that sub-therapeutic concentrations of antibiotics play a significant role in microbial acquisition of resistance by microbes. Remarkably, is the fact that human plasma can slow down growth of invading organisms but may depend on certain factors such as number of the invading organism and time it takes for antibody production and activation. After exposure of the test organism to subMICs of flucloxacillin and clindamycin it developed resistance against the two test antimicrobial agents but significantly against the narrow spectrum flucloxacillin. Therefore,to reduce the growing trend of microbial resistance, the use of sub-therapeutic concentration antibiotics should be discouraged, while the campaign against irrational use of antibiotics should continue.

\section{REFERENCES}

1. Cardile AP, Sanchez CJ, Samberg ME, Romano DR, Hardy SK Wenke JC, Murray CK, Akers KS: Human plasma enhances the expression of Staphylococcal microbial surface components recognizing adhesive matrix molecules promoting biofilm formation and increases antimicrobial tolerance In Vitro. BMC Research Notes 2014, 7:457-457.

2. Tong SYC, Davis JS, Eichenberger E, Holland TL, Fowler VG Staphylococcus aureus Infections: Epidemiology, Pathophysiology, Clinical Manifestations, and Management. Clin Microbiol Rev 2015, 28(3):603-661.

3. Meshram GG, Kaur N, Hura KS: Staphylococcal scalded skin syndrome: A pediatric dermatology case report. SAGE Open Medical Case Reports 2018, 6:2050313X17750890. 
4. Mishra AK, Yadav P, Mishra A: A Systemic Review on Staphylococcal Scalded Skin Syndrome (SSSS): A Rare and Critical Disease of Neonates. The Open Microbiology Journal 2016, 10:150159.

5. Cahill TJ, Baddour LM, Habib G, Hoen B, Salaun E, Pettersson GB Schäfers HJ, Prendergast BD: Challenges in Infective Endocarditis. Journal of the American College of Cardiology 2017, 69(3):325.

6. Okore V: Principles of Pharmaceutical Microbiology, 2nd edn. Enugu, Nigeria: EphrataPublishers; 2009.

7. Warrington R, Watson W, Kim HL, Antonetti FR: An introduction to immunology and immunopathology. Allergy, Asthma \& Clinical Immunology 2011, 7(1):S1.

8. Chaplin DD: Overview of the Immune Response. The Journal of allergy and clinical immunology 2010, 125(2 Suppl 2):S3-23.

9. Okore V, Nduka C, Ogbu H: Survival patterns of some common pathogens in human plasma following exposure to a sub-inhibitory concentration of ceftriaxone sodium. Int J Biol Chem Sci 2010, 4(3):579-586.

10. López E, Blázquez J: Effect of Subinhibitory Concentrations of Antibiotics on Intrachromosomal Homologous Recombination in Escherichia coli. Antimicrobial agents and chemotherapy 2009, 53(8):3411-3415.

11. Ventola CL: The Antibiotic Resistance Crisis: Part 2: Managemen Strategies and New Agents. Pharmacy and Therapeutics 2015, 40(5):344-352.

12. Cheng G, Dai M, Ahmed S, Hao H, Wang X, Yuan Z: Antimicrobia Drugs in Fighting against Antimicrobial Resistance. Frontiers in Microbiology 2016, 7:470.

13. Molina-Quiroz RC, Silva CA, Molina CF, Leiva LE, Reyes-Cerpa S, Contreras I, Santiviago CA: Exposure to sub-inhibitory concentrations of cefotaxime enhances the systemic colonization of Salmonella Typhimurium in BALB/c mice. Open Biology 2015, 5(10):150070.

14. Adhikari RP, Novick RP: Subinhibitory cerulenin inhibits staphylococcal exoprotein production by blocking transcription rather than by blocking secretion. Microbiology 2005, 151(9):3059-3069.

15. Dancer S: The effect of antibiotics on methicillin-resistan Staphylococcus aureus. J Antimicrob Chemother 2007, 61(2):246-253.

16. Mesak LR, Miao V, Davies J: Effects of Subinhibitory Concentrations of Antibiotics on SOS and DNA Repair Gene Expression in \&lt;em\&gt;Staphylococcus aureus\&lt;/em\&gt. Antimicrobial agents and chemotherapy 2008, 52(9):3394

17. Yim G, Wang HH, Davies J: The truth about antibiotics. International journal of medical microbiology : IJMM 2006, 296(2-3):163-170.

18. Gillespie SH, Basu S, Dickens AL, O'sullivan DM, McHugh TD: Effect of subinhibitory concentrations of ciprofloxacin on
Mycobacterium fortuitum mutation rates. J Antimicrob Chemother 2005, 56(2):344-348.

19. Cirz RT, Romesberg FE: Induction and inhibition of ciprofloxacin resistance-conferring mutations in hypermutator bacteria. Antimicrobial agents and chemotherapy 2006, 50(1):220-225.

20. Beaber JW, Hochhut B, Waldor MK: SOS response promotes horizontal dissemination of antibiotic resistance genes. Nature 2004 427(6969):72-74.

21. Lawrence JG, Roth JR: Selfish Operons: Horizontal Transfer May Drive the Evolution of Gene Clusters. Genetics 1996, 143(4):1843.

22. Cheesbrough M: Biochemical tests to identify bacteria. Laboratory Practice in Tropical Countries, Cheesbrough M (eds) Cambridge edn 2002:63-70.

23. Sandle T: 5 - Microbiological culture media. In: Pharmaceutical Microbiology. Oxford: Woodhead Publishing; 2016: 47-61.

24. Cundell AM: Review of the media selection and incubation conditions for the compendial sterility and microbial limit tests, vol. 28; 2002.

25. Ibezim C, Nwosu C, Ogbu H: Bacteriological Screening of Paediatric Cough Syrups Marketed Within Port Harcourt Metropolis, South-South Nigeria. International Journal of Pharmaceutical Sciences and Drug Research 2018, 10(2):65-70.

26. Jones C, Allsopp L, Horlick J, Kulasekara H, Filloux A: Subinhibitory Concentration of Kanamycin Induces the Pseudomonas aeruginosa type VI Secretion System. PLOS ONE 2013, 8(11):e81132.

27. Ohlsen K, Ziebuhr W, Koller K-P, Hell W, Wichelhaus TA, Hacker J: Effects of Subinhibitory Concentrations of Antibiotics on Alpha-Toxin (hla) Gene Expression of Methicillin-Sensitive and MethicillinResistant Staphylococcus aureus Isolates. Antimicrobial agents and chemotherapy 1998, 42(11):2817-2823.

28. Zhanel GG, Hoban DJ, Harding GKM: Subinhibitory antimicrobial concentrations: A review of in vitro and in vivo data. The Canadian Journal of Infectious Diseases 1992, 3(4):193-201.

29. Foster TJ: Antibiotic resistance in Staphylococcus aureus. Current status and future prospects. FEMS Microbiology Reviews 2017 , 41(3):430-449.

30. Archer NK, Mazaitis MJ, Costerton JW, Leid JG, Powers ME, Shirtliff ME: Staphylococcus aureus biofilms: properties, regulation, and roles in human disease. Virulence 2011, 2(5):445-459.

31. Bjarnsholt T, Alhede M, Alhede M, Eickhardt-Sorensen SR, Moser C, Kuhl M, Jensen PO, Hoiby N: The in vivo biofilm. Trends in microbiology 2013, 21(9):466-474.

32. Wagner C, Aytac S, Hansch GM: Biofilm growth on implants: bacteria prefer plasma coats. The International journal of artificial organs 2011, 34(9):811-817. 